\title{
Integration of automatic voltage regulator and power system stabilizer: small-signal stability in DFIG-based wind farms
}

\author{
Sirine ESSALLAH ${ }^{1}$, Adel BOUALLEGUE ${ }^{1}$, Adel KHEDHER ${ }^{1}$
}

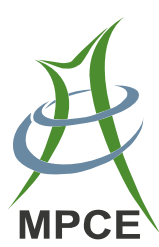

\begin{abstract}
The increasing penetration of wind farms in the energy sector directly affects the dynamic behavior of the power system. The increasing use of wind energy in the power system worsens its stability and inherently influences the firmness of a small signal. To investigate these effects, one of the synchronous generators (SGs) of the grid is considered defective and is replaced by a doubly fed induction generator (DFIG)-based wind farm of the same rating. The small-signal stability of a power system is usually evaluated via eigenvalue analysis where local-area and inter-area oscillatory modes for the New England test system are identified. SG controls, such as automatic voltage regulator (AVR) and power system stabilizer (PSS), are added to attenuate the generated disturbances. In this study, the impact of wind energy on the small-signal stability of the power system is investigated. Different combinations of AVR and PSS types are considered to mitigate the undesirable alterations. A comparative study is performed based on numerical simulations to choose the best combination of AVR and PSS types. The obtained results prove that the proposed combination yields good
\end{abstract}

CrossCheck date: 19 March 2019

Received: 18 April 2018/Accepted: 19 March 2019/Published online: 21 June 2019

(C) The Author(s) 2019

$\triangle$ Sirine ESSALLAH

sirinesallah@gmail.com

Adel BOUALLEGUE

adelbouallegue@gmail.com

Adel KHEDHER

adel_kheder@yahoo.fr

1 Université de Sousse, Ecole Nationale d'Ingénieurs de Sousse, LATIS- Laboratory of Advanced Technology and Intelligent Systems, 4023 Sousse, Tunisia results in terms of stability enhancement both under normal operating conditions and in DFIG-based wind farms.

Keywords Power system stability, Power transmission system, Transient analysis, Voltage regulation

\section{Introduction}

With the progress of economic development and increase in power demand, the electrical power system has also evolved continuously. Accordingly, the demand for new eco-friendly and economically competitive methods of electrical energy production has increased. Thus, renewable energy has recently become a large area of research. Wind is currently the most promising among several green energetic resources. Wind turbine technology has been dominant owing to its favorable technical and economic features.

One of the most commonly used wind turbine generators is a variable-speed wind turbine with a doubly fed induction generator (DFIG). The latter part can be easily connected to the grid as it provides reactive power compensation and excellent speed control [1]. Nevertheless, the continuous integration of wind power energy into the grid might affect the overall behavior of the power system [2]. Inherently, wind power fluctuations could severely alter many aspects of the operation and control of the power system such as small-signal, transient, and voltage stabilities, and frequency control. Moreover, wind power injected into the power system would redistribute the power flow of the synchronous generators (SGs), affecting the primary oscillation modes. Consequently, the power system is subjected to significant interferences and its stability is hardly maintained. Therefore, this issue must 
be thoroughly examined, particularly for the interconnection of wind farms.

Accordingly, several studies were conducted. Grid connection point, wind power penetration, and control schemes were reported in [3] to study the undesirable effects on the small-signal stability. In the same context, several studies were conducted to investigate the impact of wind power on the stability of the power system [3-5]. The authors in [6] studied the influence of the increase in load, the length of transmission lines, and penetration levels of wind energy on the stability of the power system. The impact of large solar and wind power resources on smallsignal stability was analyzed in [7]. In [8], the small-signal stability of the Western System Coordinating Council (WSCC) power system associated with a permanent magnet synchronous generator (PMSG)-based wind farm was investigated. The obtained results show that, when the wind farm capacity changes, the type of transmission line between the PMSG-based wind farm and the power grid affects the stability of the system. A comparative analysis of three different types of wind turbines interconnected with the IEEE 9-bus system was performed in [9]. The study based on the analysis of eigenvalues proves that the isolation of the converter reduces the small-signal stability. In [10], the impact of the high penetration of wind energy on the oscillatory stability of the rotor is discussed. This reference shows that an increase in the wind energy penetration enhances the damping of the inter-area oscillations and reduces the weak tie-line stress. The dynamic behavior of DFIG was examined in $[11,12]$. These studies focused on the determination of the impact of DFIG on power system dynamics, the response to grid disturbances, and the control strategies to assimilate the behavior of a DFIG to an SG [13, 14].

In [15], the stability issue of the grid for a DFIG-based wind farm was analyzed. The impact of power system stabilizer (PSS) and a static series synchronous compensator (SSSC) on the stability of wind power systems was studied. The investigations performed show that, with the coordinated control of PSS and SSSC, power system oscillations are minimized, whereas transient and smallsignal stabilities are enhanced. Furthermore, the capabilities of an SG and DFIG under extreme disturbances are intensified. The influence of a DFIG-based wind turbine on the rotor angle stability was reported in [16]. A control strategy for both DFIG rotor-side converter (RSC) and grid-side converter (GSC) was proposed to mitigate the impact of DFIG on the system stability. The GSC control scheme is analogous to a static compensator. The latter part provides reactive power support during grid faults. Moreover, the PSS was implemented in the reactive power control loop of DFIG-RSC to enhance the rotor angle stability. These propositions were verified using an IEEE 9-bus test system during both small and large disturbances. In [17], the authors proposed a predictive control scheme to enhance the stability of the modified IEEE 39-bus test system along with a DFIG-based wind farm considering both the supercapacitor energy storage system and SSSC. The PSS and SSSC controllers ensure the minimization of the power system oscillations. However, if these oscillations are not controlled, they might lead to deviations in the speed and angle of the rotor and variations of the tie-line flow of the power. The impact of a DFIG-based wind turbine generator on transient and small-signal stabilities was examined in [18]. Numerical simulations prove that the integration of DFIG improves the transient and smallsignal stabilities. Moreover, the presence of PSS in both DFIG and SG reduces the oscillation and improves the damping torque. The authors in [19] proposed a simple and systematic approach to investigate the impact of DFIG integration on the stability of the power system using damping ratio sensitivity to inertia. The impact of this approach could be positive or negative depending on the location of the DFIG. The negative impact might be improved using power oscillation dampers. Diverse issues related to the integration of DFIG into the power system were surveyed in [20].

The aforementioned overviews mainly focused on the analysis of transient and small-signal stabilities with the integration of DFIG-based wind farms for a single-machine infinite-bus system. However, less attention was paid to multi-machine systems. Moreover, for automatic voltage regulator (AVR) and PSS controllers, the most commonly used types are the IEEE type 1 for the AVR and the leadlag-based structure for the PSS. However, other existing types could provide better results in terms of damping of power oscillations.

The investigations in this study are performed on a multi-machine system using combinations of several types of AVR and PSS controllers. The impact of DFIG on the small-signal stability of an IEEE 39-bus power system with and without controllers is verified. The impact of replacing the conventional SGs with equivalent DFIG wind farms on the oscillation modes of the power system and their damping characteristics are analyzed. Different types of AVR and PSS controllers are considered and the best combination that improves the stability of the power system in the presence of wind farms is selected.

\section{Small-signal stability analysis}

The stability of an electric power system is defined as its ability to maintain an equilibrium state both under normal conditions and when subjected to a physical disturbance. Small-signal rotor angle stability is defined as the ability of 
a power system to remain in synchronism mode under small load variations or decoupled generators. In this case, the disturbances are considered sufficiently small to linearize the system equations. The instability results in rotor oscillations with increased amplitude owing to the lack of damping torque and an aperiodic mode resulting from the lack of synchronizing torque.

\subsection{Oscillatory modes}

Small-signal stability analysis is substantial for electromechanical oscillation modes. It concerns individual generator rotor or generator groups swinging against each other. Electromechanical oscillation modes might be classified into inter-area modes with a frequency range from 0.16 to $0.7 \mathrm{~Hz}$ and local-area modes with a frequency range from 0.7 to $2 \mathrm{~Hz}$ [21].

To achieve small-signal stability, these modes should be properly damped. The integration of control devices such as AVR and PSS is of great importance for the damping of these modes. This can be evaluated using eigenvalue analysis.

\subsection{Eigenvalue computation}

The behavior of a dynamical system is given by:

$\left\{\begin{array}{l}\dot{\boldsymbol{x}}=\boldsymbol{f}(\boldsymbol{x}, \boldsymbol{z}, \boldsymbol{u}) \\ \mathbf{0}=\boldsymbol{g}(\boldsymbol{x}, z, \boldsymbol{u})\end{array}\right.$

where $\boldsymbol{x}=\left[x_{1}, x_{2}, \ldots, x_{n}\right]$ is the state vector of the system, $n$ is the order of the system; $z$ is the vector of algebraic output variables (i.e. $\boldsymbol{V}$ and $\boldsymbol{\theta}$ ); and $\boldsymbol{u}$ is the vector of algebraic input variables. The linearization of (1) is an important step to study the power system response under small variations. At equilibrium, all state derivatives are null. The differential equations are arranged in a state-space form and the resulting linear system is given as:

$\left\{\begin{array}{c}\Delta \dot{x}=A \Delta x+B \Delta z \\ 0=C \Delta x+D \Delta z\end{array}\right.$

where $\boldsymbol{A}, \boldsymbol{B}, \boldsymbol{C}, \boldsymbol{D}$ are the state, input, output and coefficient matrices, respectively.

For the perturbation model of the small signal, $\Delta x$ and $\Delta z$ are given by:

$\left\{\begin{array}{lll}\Delta \boldsymbol{x} & =\left[\begin{array}{llllll}\Delta \boldsymbol{\delta} & \Delta \boldsymbol{\omega} & \Delta \boldsymbol{e}\end{array}\right]^{\mathrm{T}} \\ \Delta \boldsymbol{z} & =\left[\begin{array}{llllll}\Delta \boldsymbol{\theta}_{1} & \Delta \boldsymbol{\theta}_{2} & \Delta \boldsymbol{\theta}_{3} & \Delta \boldsymbol{V}_{1} & \Delta \boldsymbol{V}_{2} & \Delta \boldsymbol{V}_{3}\end{array}\right]^{\mathrm{T}}\end{array}\right.$

where $\Delta \delta$ and $\Delta \omega$ are the vectors of variation of rotor angluar position and rotor speed of SGs, respectively; $\Delta \boldsymbol{e}$ is the vector of other state variables of SGs; $\Delta \boldsymbol{\theta}_{1}, \Delta \boldsymbol{\theta}_{2}$ and $\Delta \boldsymbol{\theta}_{3}$ are the vectors of variation of SGs voltage phase; and $\Delta \boldsymbol{V}_{1}, \Delta \boldsymbol{V}_{2}$ and $\Delta \boldsymbol{V}_{3}$ are the vectors of variation of SGs voltage amplitude.
Laplace transform is subsequently applied to (3) and the linearized state equation is computed. Finally, by solving (4), the eigenvalues $\lambda_{i}$ are obtained.

$\operatorname{det}\left(\boldsymbol{A}-\lambda_{i} \boldsymbol{I}\right)=0$

where $\boldsymbol{I}$ is the identity matrix. The damping ratio $\zeta_{i}$ and the oscillation frequency $f_{i}$ for each mode $i$ are computed from

$\left\{\begin{array}{l}\lambda_{i}=\sigma_{i} \pm \mathrm{j} \omega_{i} \\ \zeta_{i}=\frac{-\sigma_{i}}{\sqrt{\sigma_{i}^{2}+\omega_{i}^{2}}} \\ f_{i}=\frac{\omega_{i}}{2 \pi}\end{array}\right.$

The analysis of eigenvalues allows us to draw conclusions about the stability of the system. Real eigenvalues are related to the non-oscillatory mode, whereas complex eigenvalues are related to the oscillatory mode. Indeed, the negative real parts of eigenvalues denote that the systems are stable. A low positive value of damping ratio denotes that the system is stable but sensitive to instability compared with other systems with higher damping ratios. Thus, eigenvalues with the lowest damping ratios are considered for the small-signal stability analysis.

\section{DFIG}

The commonly used structure of a variable-speed wind turbine based on DFIG is illustrated in Fig. 1. The steadystate electrical equations of the DFIG are given as [22]:

1) Stator voltage equation

$\left\{\begin{array}{l}v_{d s}=-R_{s} i_{d s}+\left(x_{s}+x_{m}\right) i_{q s}+x_{m} i_{q r} \\ v_{q s}=-R_{s} i_{q s}+\left(x_{s}+x_{m}\right) i_{d s}+x_{m} i_{d r}\end{array}\right.$

2) Rotor voltage equation

$\left\{\begin{array}{l}v_{d r}=-R_{r} i_{d r}+\left(1-\omega_{m}\right)\left[\left(x_{r}+x_{m}\right) i_{q r}+x_{m} i_{q s}\right] \\ v_{q r}=-R_{r} i_{q r}+\left(1-\omega_{m}\right)\left[\left(x_{r}+x_{m}\right) i_{d r}+x_{m} i_{d s}\right]\end{array}\right.$

where $v_{d s}$ and $v_{q s}$ are the $d q$-axes stator voltages; $i_{d s}$ and $i_{q s}$ are the $d q$-axes stator currents; $v_{d r}$ and $v_{q r}$ are the $d q$-axes

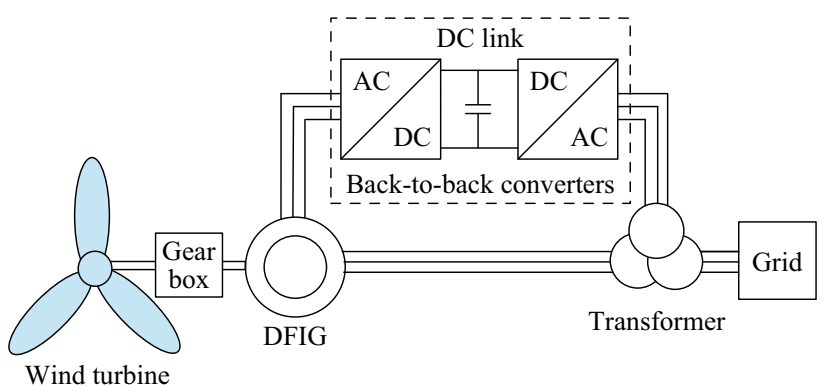

Fig. 1 Wind energy conversion system (WECS) using DFIG structure 
rotor voltages; $i_{d r}$ and $i_{q r}$ are the $d q$-axes rotor currents; $R_{s}$ and $R_{r}$ are the stator and rotor resistances; $x_{s}, x_{r}, x_{m}$ are the stator and rotor self-reactances and mutual reactance, respectively; and $\omega_{m}$ is the relative rotor speed.

The active and reactive powers $(P$ and $Q$ ) injected into the grid depend on the stator currents and the grid-side currents $\left(i_{d g}\right.$ and $\left.i_{q g}\right)$ of the converter. These currents are given by:

$$
\left\{\begin{array}{l}
P=v_{d s} i_{d s}+v_{q s} i_{q s}+v_{d g} i_{d g}+v_{q g} i_{q g} \\
Q=v_{q s} i_{d s}-v_{d s} i_{q s}+v_{q g} i_{d g}-v_{d g} i_{q g}
\end{array}\right.
$$

where $v_{d g}$ and $v_{q g}$ are the grid-side voltages.

These equations can be rewritten using the power equations of the converter, as shown below. The powers of the converter on the grid side are given by:

$$
\left\{\begin{array}{l}
P_{g}=v_{d g} i_{d g}+v_{q g} i_{q g} \\
Q_{g}=v_{d g} i_{d g}-v_{d g} i_{q g}
\end{array}\right.
$$

whereas, on the rotor side, they are given by:

$$
\left\{\begin{array}{l}
P_{r}=v_{d r} i_{d r}+v_{q r} i_{q r} \\
Q_{r}=v_{q r} i_{d r}-v_{d r} i_{q r}
\end{array}\right.
$$

Assuming a lossless converter model and a unity power factor on the converter grid side:

$\left\{\begin{array}{c}P_{g}=P_{r} \\ Q_{g}=0\end{array}\right.$

Therefore, the powers injected into the grid are obtained as:

$\left\{\begin{array}{l}P=v_{d s} i_{d s}+v_{q s} i_{q s}+v_{d r} i_{d r}+v_{q r} i_{q r} \\ Q=v_{q s} i_{d s}-v_{d s} i_{q s}\end{array}\right.$

The effects of wind penetration on this system are examined by replacing one of the SGs at a time with an equivalent wind farm of the same power capacity. The DFIG-based wind turbine connection in power system analysis foolbox (PSAT) is shown in Fig. 2. The wind speed model associated with the DFIG is the Weibull distribution [23], as illustrated in Fig. 3.

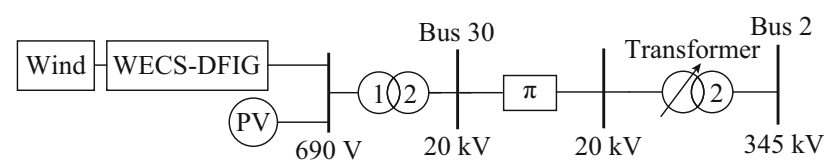

Fig. 2 Wind farm connection system in PSAT

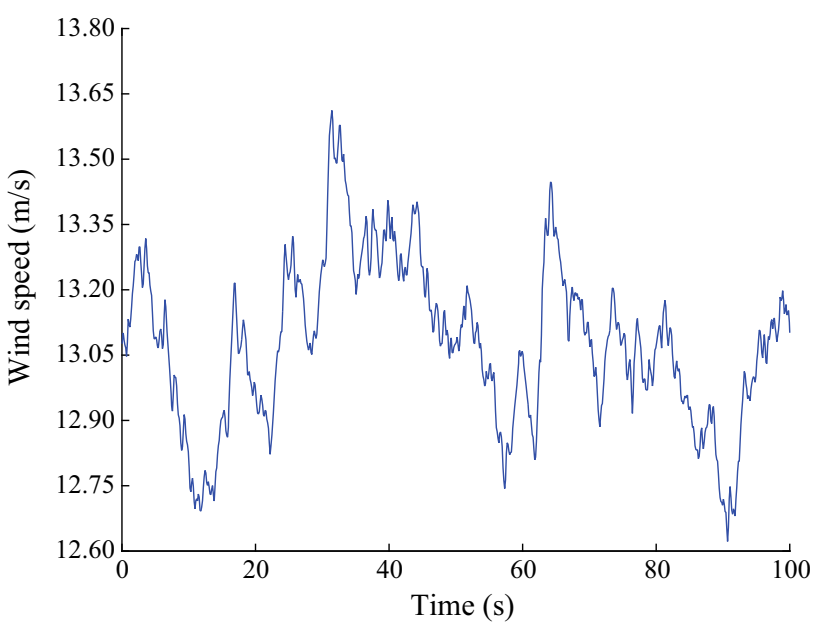

Fig. 3 Weibull distribution wind speed

\section{Test system description}

\subsection{System characteristics}

The 39-bus system shown in Fig. 4 is used for the smallsignal stability analysis associated with DFIG. This system consists of 39 buses with 10 SGs, 12 transformers, 34 transmission lines and 19 loads. The total active and reactive powers in the basic configuration are $6145.97 \mathrm{MW}$ and 1363.41 Mvar, respectively. The voltage levels of the test system are $20 \mathrm{kV}, 115 \mathrm{kV}$ and $345 \mathrm{kV}$ indicated in Fig. 4 with red, blue and black colors, respectively. The numerical investigations were performed using PSAT MATLAB/Simulink and Simulation tools used for power system analysis [24]. All the data used for the implementation of the system in PSAT are given in [25].

\subsection{Dynamic modeling}

In this section, the dynamic models of SGs, exciters, and power stabilizers for the IEEE 39-bus system are described.

\subsubsection{Generators}

The link between the network phasors and the SG voltages is given by:

$\left\{\begin{array}{l}v_{d}=V \sin (\delta-\theta) \\ v_{q}=V \cos (\delta-\theta)\end{array}\right.$

where $v_{d}$ and $v_{q}$ are the $d q$-axes voltages; $\delta$ and is the rotor angular position; and $\theta$ is the phase voltage.

The expressions of $d q$-axes currents depend on the chosen model. In this study, a fourth-order model is adopted where $\delta, \omega, e_{d}^{\prime}$ and $e_{q}^{\prime}$ are the state variables. Lead-lag transfer functions are used to model the $d q$-axes 


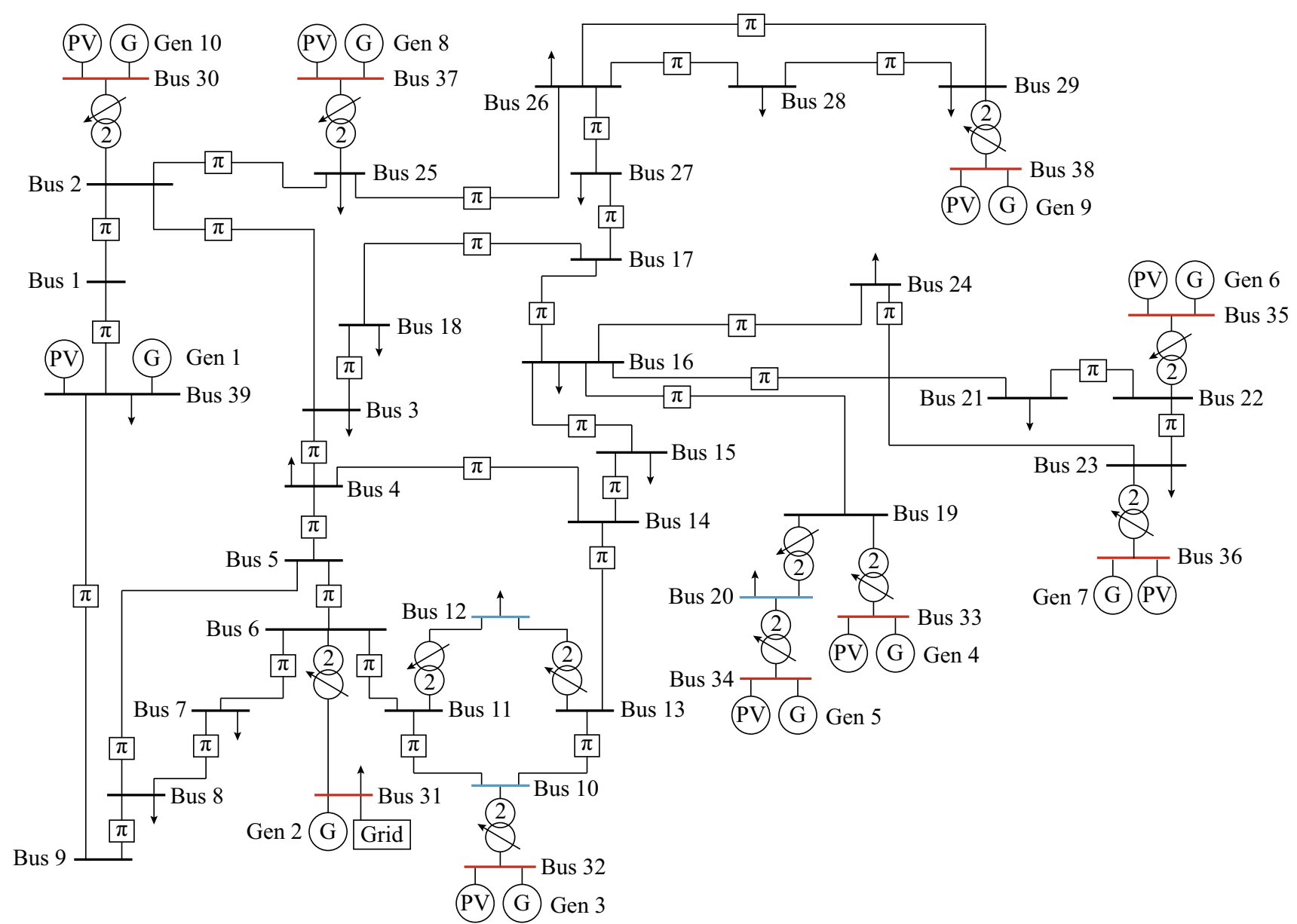

Fig. 4 IEEE 39-bus test system in PSAT

inductances. The differential algebraic equations (DAEs) are given by:

$$
\left\{\begin{array}{l}
\frac{\mathrm{d} \delta}{\mathrm{d} t}=\Omega_{b}(\omega-1) \\
\frac{\mathrm{d} \omega}{\mathrm{d} t}=\left[p_{m}-p_{e}-D(\omega-1)\right] / M \\
\frac{\mathrm{d} e_{q}^{\prime}}{\mathrm{d} t}=\left[-f_{s} e_{q}^{\prime}-\left(x_{d}-x_{d}^{\prime}\right) i_{d}+v_{f}^{*}\right] / T_{d 0}^{\prime} \\
\frac{\mathrm{d} e_{d}^{\prime}}{\mathrm{d} t}=\left[-e_{d}^{\prime}+\left(x_{q}-x_{q}^{\prime}\right) i_{q}\right] / T_{q 0}^{\prime}
\end{array}\right.
$$

where $i_{d}$ and $i_{q}$ are the $d q$-axes currents; $e_{d}^{\prime}$ and $e_{q}^{\prime}$ are the $d q$-axes transient voltages; $x_{d}$ and $x_{q}$ are the $d q$-axes synchronous reactances; $x_{d}^{\prime}$ and $x_{q}^{\prime}$ are the $d q$-axes transient reactances; $T_{d 0}^{\prime}$ and $T_{q 0}^{\prime}$ are the $d q$-axes open-circuit time constants; $D$ is the damping coefficient; $M=2 H$ is the mechanical starting time, $H$ is the inertia constant; $\omega$ is the rotor speed; $\Omega_{b}$ is the relative rotor speed; $f_{s}$ is the frequency rating; and $v_{f}^{*}$ is the modified field voltage.
The electrical power $p_{e}$ and the field voltage are defined as follows:

$$
\begin{aligned}
& p_{e}=\left(v_{q}+r_{a} i_{q}\right) i_{q}+\left(v_{d}+r_{a} i_{d}\right) i_{d} \\
& v_{f}^{*}=v_{f}+K_{\omega}(\omega-1)+K_{p}\left(P_{m}-P(\boldsymbol{x}, \boldsymbol{V}, \boldsymbol{\theta})\right)
\end{aligned}
$$

where $P_{m}$ is the mechanical power; $r_{a}$ is the armature resistance; $v_{f}$ is the field voltage; $P$ is the active power produced by the machine; and $K_{\omega}$ and $K_{p}$ are the speed and active power feedback gains. The voltage and current relationships are described by the following equations:

$$
\left\{\begin{array}{l}
0=v_{d}+r_{a} i_{d}-e_{d}^{\prime}-\left(x_{q}^{\prime}-x_{l}\right) i_{q} \\
0=v_{q}+r_{a} i_{q}-e_{q}^{\prime}+\left(x_{d}^{\prime}-x_{l}\right) i_{d}
\end{array}\right.
$$

where $x_{l}$ is the leakage reactance.

Considering (14) to (17), the electrical power is obtained as:

$p_{e}=\left(e_{q}^{\prime}-x_{d}^{\prime} i_{d}\right) i_{q}+\left(e_{d}^{\prime}+x_{q}^{\prime} i_{q}\right) i_{d}$

The DAEs for each machine are thus expressed as: 


$$
\left\{\begin{array}{l}
\frac{\mathrm{d} \delta_{i}}{\mathrm{~d} t}=\Omega_{b}\left(\omega_{i}-1\right) \\
\frac{\mathrm{d} \omega_{i}}{\mathrm{~d} t}=\frac{p_{m i}}{M_{i}}-\frac{e_{q i}^{\prime}-x_{d i}^{\prime} i_{d i}}{M_{i}} i_{q i}-\frac{e_{d i}^{\prime}+x_{q i}^{\prime} i_{q i}}{M_{i}} i_{d i}-\frac{D_{i}\left(\omega_{i}-1\right)}{M_{i}} \\
\frac{\mathrm{d} e_{q i}^{\prime}}{\mathrm{d} t}=-\frac{f_{s} e_{q i}{ }^{\prime}}{T_{d 0 i}^{\prime}}-\frac{x_{d i}-x_{d i}^{\prime}}{T_{d 0 i}^{\prime}} i_{d i}+\frac{v_{f i}^{*}}{T_{d 0 i}^{\prime}} \\
\frac{\mathrm{d} e_{d i}^{\prime}}{\mathrm{d} t}=-\frac{e_{d i}^{\prime}}{T_{q 0 i}^{\prime}}+\frac{i_{q i}}{T_{q 0 i}^{\prime}}\left(x_{q i}-x_{q i}^{\prime}\right)
\end{array}\right.
$$

The linearization of the differential system (19) yields:

$$
\left\{\begin{aligned}
\frac{\mathrm{d} \Delta \delta_{i}}{\mathrm{~d} t} & =\Omega_{b} \Delta \omega_{i} \\
\frac{\mathrm{d} \Delta \omega_{i}}{\mathrm{~d} t} & =\frac{1}{M_{i}} \Delta p_{m i}-\frac{e_{q i 0}^{\prime}}{M_{i}} \Delta i_{q i}+\frac{x_{d i}^{\prime} i_{d i 0}}{M_{i}} \Delta i_{q i}+\frac{x_{d i}^{\prime} i_{q i 0}}{M_{i}} \Delta i_{d i}-\frac{i_{q i 0}}{M_{i}} \Delta e_{q i}^{\prime} \\
& -\frac{i_{d i 0}}{M_{i}} \Delta e_{d i}^{\prime}-\frac{e_{d i 0}^{\prime}}{M_{i}} \Delta i_{d i}-\frac{x_{q i}^{\prime} i_{q i 0}}{M_{i}} \Delta i_{d i}-\frac{x_{q i}^{\prime} i_{d i 0}}{M_{i}} \Delta i_{q i}-\frac{D_{i}}{M_{i}} \Delta \omega_{i} \\
\frac{\mathrm{d} \Delta e_{q i}^{\prime}}{\mathrm{d} t} & =-\frac{f_{s} \Delta e_{q i}^{\prime}}{T_{d 0 i}^{\prime}}-\frac{x_{d i}-x_{d i}^{\prime}}{T_{d 0 i}^{\prime}} \Delta i_{d i}+\frac{\Delta v_{f i}^{*}}{T_{d 0 i}^{\prime}} \\
\frac{\mathrm{d} \Delta e_{d i}^{\prime}}{\mathrm{d} t} & =-\frac{\Delta e_{d i}^{\prime}}{T_{q 0 i}^{\prime}}+\frac{\Delta i_{q i}}{T_{q 0 i}^{\prime}}\left(x_{q i}-x_{q i}^{\prime}\right)
\end{aligned}\right.
$$

Writing (20) in matrix notation, we obtain the state matrix $\boldsymbol{A}$ as follows:

$$
\begin{aligned}
{\left[\begin{array}{c}
\Delta \dot{\delta}_{i} \\
\Delta \dot{\omega}_{i} \\
\Delta \dot{e}_{q i}^{\prime} \\
\Delta \dot{e}_{d i}^{\prime}
\end{array}\right] } & {\left[\begin{array}{cccc}
0 & \Omega_{b} & 0 & 0 \\
0 & -\frac{D_{i}}{M_{i}} & -\frac{i_{q i 0}}{M_{i}} & -\frac{i_{d i 0}}{M_{i}} \\
0 & \frac{K_{\omega}}{T_{d 0 i}^{\prime}} & -\frac{f_{s}}{T_{d 0 i}^{\prime}} & 0 \\
0 & 0 & 0 & -\frac{1}{T_{q 0 i}^{\prime}}
\end{array}\right] } \\
& \times\left[\begin{array}{c}
\Delta \delta_{i} \\
\Delta \omega_{i} \\
\Delta e_{q i}^{\prime} \\
\Delta e_{d i}^{\prime}
\end{array}\right] \quad 1 \leq i \leq 10
\end{aligned}
$$

As already mentioned, each SG is defined by four state variables; thus, for a power system with $10 \mathrm{SGs}$, the dimensions of the state matrix $\boldsymbol{A}$ are $40 \times 40$.

\subsubsection{AVR}

It defines the primary voltage regulation of the SG. AVR measures the bus terminal voltage of the machine, compares it with the reference voltage, and then uses the error signal to modify the field voltage of the rotor. In this work, three types of AVRs are considered. The best amongst them is then chosen based on a comparative study.

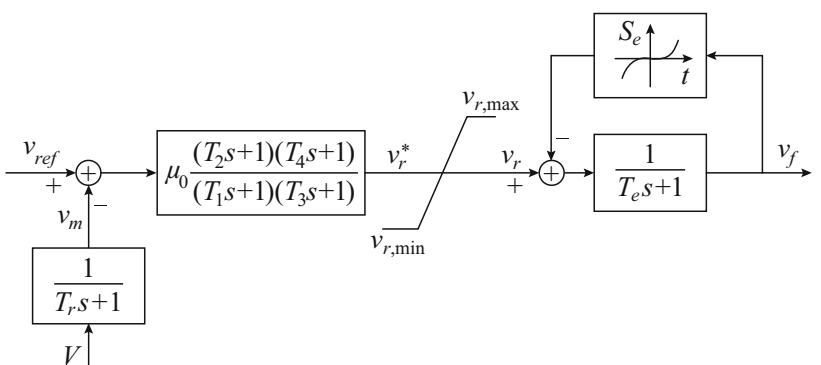

(a) AVR type 1

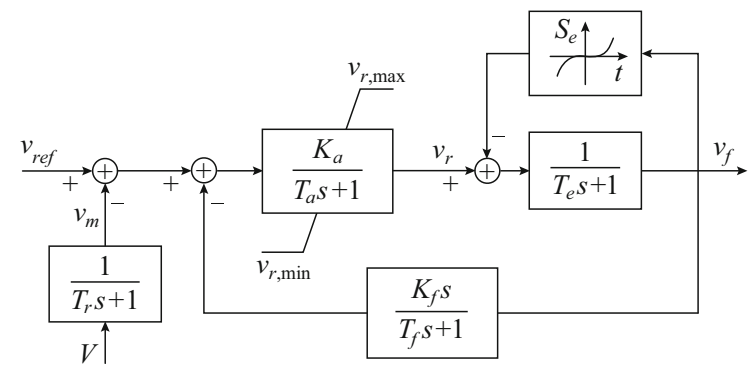

(b) AVR type 2

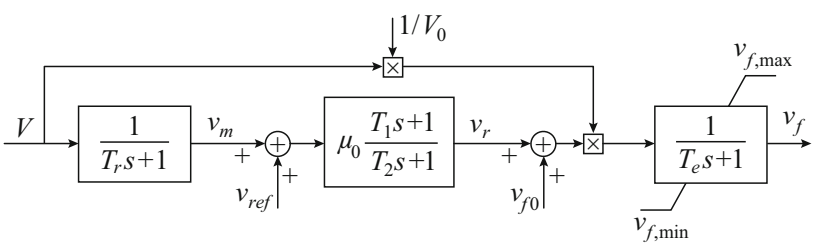

(c) AVR type 3

Fig. 5 Different AVR types

1) AVR type 1

The structure of this AVR type is depicted in Fig. 5a and is expressed by:

$$
\left\{\begin{array}{l}
\dot{v}_{m}=\frac{V-v_{m}}{T_{r}} \\
\dot{v}_{r 1}=\frac{1}{T_{1}}\left[\mu_{0}\left(1-\frac{T_{2}}{T_{1}}\right)\left(v_{r e f}-v_{m}\right)-v_{r 1}\right] \\
\dot{v}_{r 2}=\frac{1}{T_{4}}\left[\left(1-\frac{T_{3}}{T_{4}}\right)\left(v_{r 1}+\mu_{0} \frac{T_{2}}{T_{1}}\left(v_{r e f}-v_{m}\right)-v_{r 2}\right]\right. \\
v_{r}^{*}=v_{r 2}+\frac{T_{3}}{T_{4}}\left[v_{r 1}+\mu_{0} \frac{T_{2}}{T_{1}}\left(v_{r e f}-v_{m}\right)-v_{r 1}\right] \\
\dot{v}_{f}=-\frac{1}{T_{e}}\left[v_{f}\left(1+S_{e}\left(v_{f}\right)\right)-v_{r}\right]
\end{array}\right.
$$

where $v_{r e f}$ is the reference voltage of the AVR; $v_{m}, v_{r}$ and $v_{f}$ are the outputs of the measurement circuit, AVR, and excitation system stabilizer (feedback), respectively; $\mu_{0}$ is the regulator gain; $T_{1}, T_{2}, T_{3}$ and $T_{4}$ are the AVR time constants; $T_{e}$ and $T_{r}$ are the field circuit and measurement time constants, respectively; $v_{r \text {,min }}$ and $v_{r \text {,max }}$ are the lower and upper limits of $v_{r}$ (the exciter ceiling voltages), 
respectively; $v_{r 1}$ and $v_{r 2}$ are the amplifier state variable and stabilizer state variable; and $S_{e}$ is the saturation function of the exciter defined as:

$$
S_{e}\left(v_{f}\right)=A_{e}\left(\mathrm{e}^{B_{e}\left|v_{f}\right|}-1\right)
$$

where $A_{e}$ and $B_{e}$ are constants chosen to match the opencircuit magnetization curve at two points, usually $v_{f, \max }$ and $0.75 v_{f, \max }[24,26]$.

2) AVR type 2

This excitation model is expressed by the following equations:

$$
\left\{\begin{array}{l}
\frac{\mathrm{d} v_{r 1}}{\mathrm{dt}}=\frac{1}{T_{a}}\left[K_{a}\left(v_{r e f}-v_{m}-v_{r 2}-\frac{K_{f}}{T_{f}} v_{f}\right)-v_{r 1}\right] \\
\frac{\mathrm{d} v_{m}}{\mathrm{dt}}=\frac{V-v_{m}}{T_{r}} \\
\frac{\mathrm{d} v_{f}}{\mathrm{dt}}=-\frac{1}{T_{e}}\left[v_{f}\left(1+S_{e}\left(v_{f}\right)\right)-v_{r}\right] \\
\frac{\mathrm{d} v_{r 2}}{\mathrm{dt}}=-\frac{1}{T_{f}}\left(\frac{K_{f}}{T_{f}} v_{f}+v_{r 2}\right)
\end{array}\right.
$$

where $K_{a}, K_{f}, T_{f}$ are the amplifier gain, stabilizer gain and stabilizer time constant.

Its structure is depicted in Fig. $5 b$.

3) AVR type 3

The last type of AVR is shown in Fig. $5 c$ and its descriptive equations are given as:

$$
\left\{\begin{array}{l}
\dot{v}_{m}=\frac{V-v_{m}}{T_{r}} \\
\dot{v}_{r}=\frac{1}{T_{2}}\left[\mu_{0}\left(1-\frac{T_{1}}{T_{2}}\right)\left(v_{r e f}-v_{m}\right)-v_{r}\right] \\
\dot{v}_{f}=\frac{1}{T_{e}}\left[\left(v_{r}+\mu_{0} \frac{T_{1}}{T_{2}}\left(v_{r e f}-v_{m}\right)+v_{f 0}\right) \frac{V}{V_{0}}-v_{f}\right]
\end{array}\right.
$$

where $v_{f 0}$ is the initial field voltage; and $V_{0}$ is the bus voltage offset.

\subsubsection{PSS}

They are supplementary control devices installed at the generator excitation systems. Their main function is to improve the stability by damping power system oscillations [27]. Three PSS types are considered in this study. The best type among them is chosen using the following tests.

\section{1) PSS type 1}

The first PSS type depicted in Fig. 6a is expressed by the following equations:

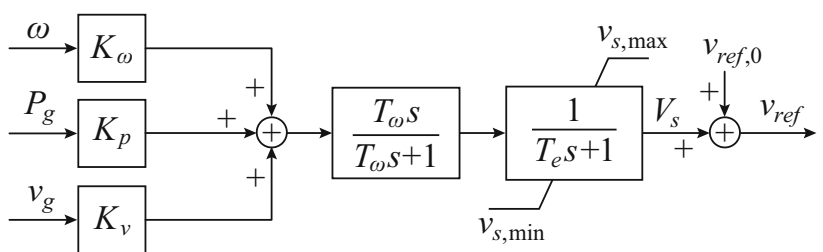

(a) PSS type 1

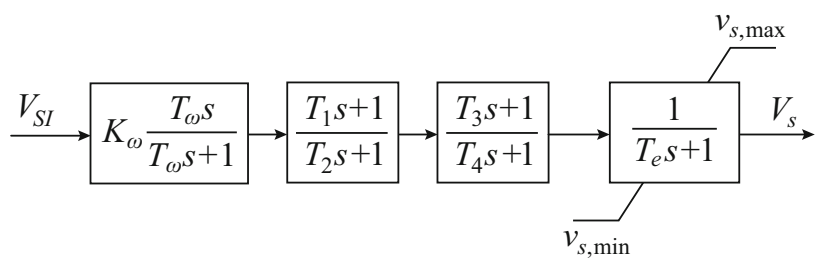

(b) PSS type 2

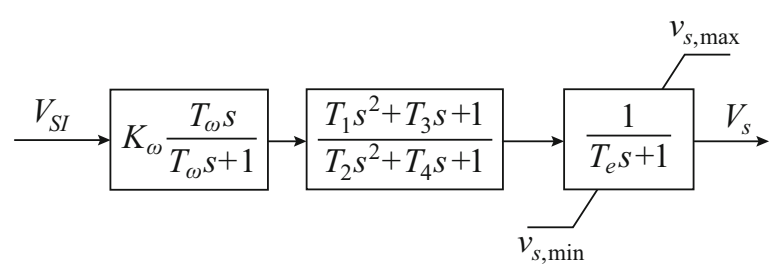

(c) PSS type 3

Fig. 6 Different PSS types

$$
\left\{\begin{array}{l}
\dot{v}_{1}=-\left(K_{\omega} \omega+K_{p} P_{g}+K_{v} V_{g}+v_{1}\right) / T_{\omega} \\
\dot{v}_{s}=\left(K_{\omega} \omega+K_{p} P_{g}+K_{v} V_{g}+v_{1}-v_{s}\right) / T_{e}
\end{array}\right.
$$

where $v_{1}$ and $v_{s}$ are the washout circuit and PSS output signals, respectively; $P_{g}$ and $V_{g}$ are the active power and voltage magnitude of the SG to which the PSS is connected, respectively; $K_{v}$ is the voltage gain; and $T_{\omega}$ and $T_{e}$ are the wash-out and anti-windup limiter time constants, respectively.

2) PSS type 2

The second type of PSS shown in Fig. $6 \mathrm{~b}$ is expressed by the following equations:

$$
\left\{\begin{array}{l}
\dot{v}_{1}=-\frac{K_{\omega} V_{S I}+v_{1}}{T_{\omega}} \\
\dot{v}_{2}=\frac{1}{T_{2}}\left[\left(1-\frac{T_{1}}{T_{2}}\right)\left(K_{\omega} V_{S I}+v_{1}\right)-v_{2}\right] \\
\dot{v}_{3}=\frac{1}{T_{4}}\left\{\left(1-\frac{T_{3}}{T_{4}}\right)\left[v_{2}+\frac{T_{1}}{T_{2}}\left(K_{\omega} V_{S I}+v_{1}\right)\right]-v_{3}\right\} \\
\dot{v}_{s}=\frac{1}{T_{e}}\left\{v_{3}+\frac{T_{3}}{T_{4}}\left[v_{2}+\frac{T_{1}}{T_{2}}\left(K_{\omega} V_{S I}+v_{1}\right)\right]-v_{s}\right\}
\end{array}\right.
$$

where $V_{S I}$ is the power system stabilizer input signal.

3) PSS type 3

The third type of PSS presented in Fig. $6 c$ is expressed by the following equations: 


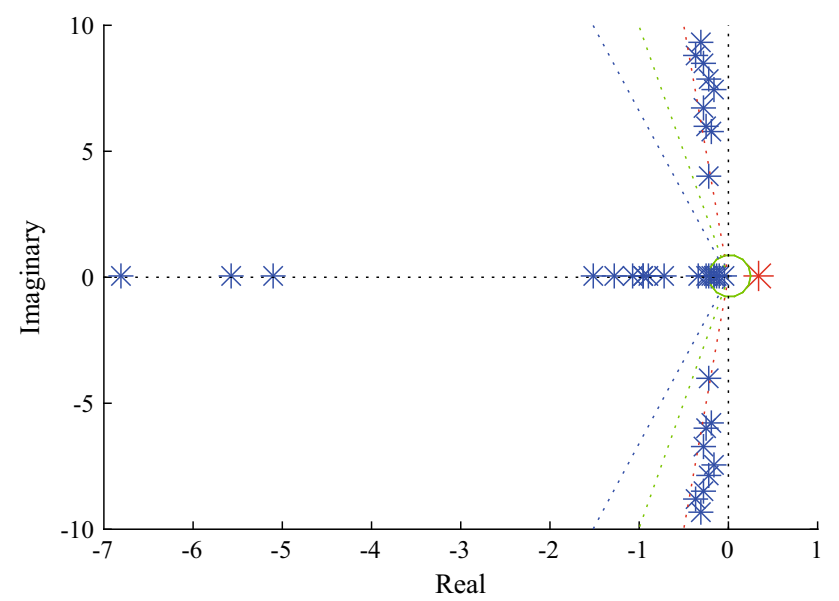

Fig. 7 Eigenvalue plot for case 1

$$
\left\{\begin{array}{l}
\dot{v}_{1}=-\frac{K_{\omega} V_{S I}+v_{1}}{T_{\omega}} \\
\dot{v}_{2}=\frac{1}{T_{4}} v_{3}+\frac{1}{T_{4}}\left(T_{1}-T_{2} \frac{T_{3}}{T_{4}}\right)\left(K_{\omega} V_{S I}+v_{1}\right) \\
\dot{v}_{3}=-v_{2}-\frac{T_{2}}{T_{4}} v_{3}+\left[1-\frac{T_{3}}{T_{4}}-\frac{T_{2}}{T_{4}}\left(T_{1}-T_{2} \frac{T 3}{T 4}\right)\right]\left(K_{\omega} V_{S I}+v_{1}\right) \\
\dot{v}_{s}=\frac{1}{T_{e}}\left[v_{2}+\frac{T_{3}}{T_{4}}\left(K_{\omega} V_{S I}-v_{1}\right)-v_{s}\right]
\end{array}\right.
$$

\section{Results and discussion}

\subsection{Test scenarios}

Five different scenarios were considered in this study.

1) Case 1: all the power system generators are equivalent to SGs without any control devices.

2) Case 2: different combinations of AVR and PSS types are integrated in the SGs. The combination yielding the best results in terms of the damping of rotor angle oscillations is chosen.

3) Case 3: one of the SGs is replaced by a DFIG of the same power capacity and the remaining SGs are operated without controllers.

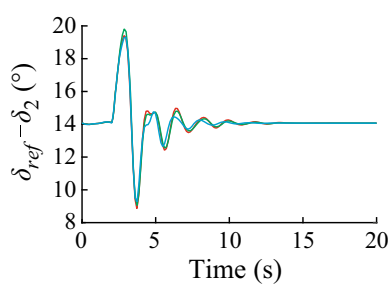

$$
\begin{aligned}
& \text { - AVR type 1+PSS type } 3 \\
& \text { - AVR type 1+PSS type } 2 \\
& \text { - AVR type 1+PSS type } 1
\end{aligned}
$$

(a) AVR type 1 with different PSSs

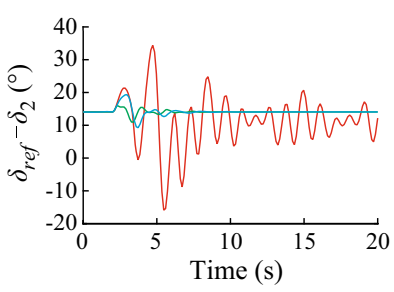

- PSS type $1+$ AVR type 2

- PSS type 1+AVR type 3

- PSS type 1+AVR type 1

(b) PSS type 1 with different AVRs

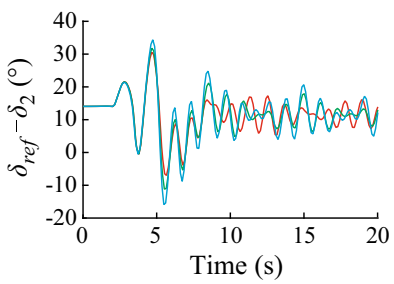

- AVR type 2+PSS type 3

- AVR type 2+PSS type 2

- AVR type 2+PSS type 1

(c) AVR type 2 with different PSSs

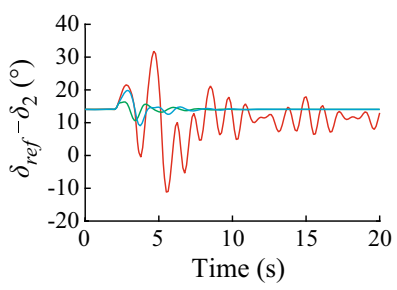

- PSS type 2+AVR type 2

- PSS type 2+AVR type 3

- PSS type 2+AVR type 1

(d) PSS type 2 with different AVRs

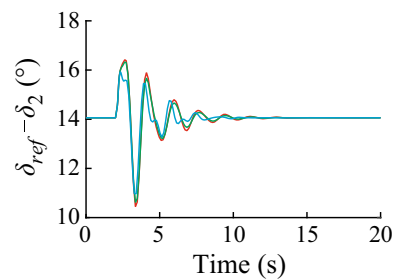

- AVR type 3+PSS type 3

- AVR type $3+$ PSS type 2

- AVR type 3+PSS type 1

(e) AVR type 3 with different PSSs

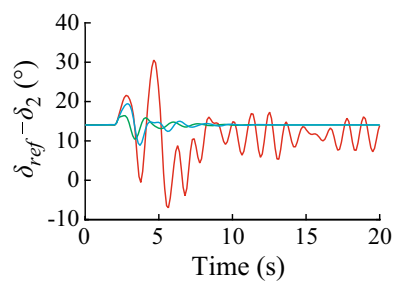

- PSS type 3+AVR type 2

- PSS type 3+AVR type 3

- PSS type 3+AVR type 1

(f) PSS type 3 with different AVRs

Fig. 8 Transient response of SG rotor angle $\delta_{\text {ref }}-\delta_{2}$ against a threephase fault under different combinations of AVR and PSS types

4) Case 4: one of the SGs is replaced by a DFIG and the remaining SGs are equipped with the chosen combination of AVR and PSS.

\begin{tabular}{|c|c|c|c|c|c|c|}
\hline \multirow[t]{2}{*}{ AVR type } & \multicolumn{3}{|c|}{ MRADR (\%) } & \multicolumn{3}{|c|}{ Oscillation period (s) } \\
\hline & PSS type 1 & PSS type 2 & PSS type 3 & PSS type 1 & PSS type 2 & PSS type 3 \\
\hline 1 & 37.13 & 40.89 & 38.05 & 8.48 & 9.24 & 10.35 \\
\hline 2 & 51.78 & 53.34 & 53.48 & 84.35 & 66.26 & 58.15 \\
\hline 3 & 10.88 & 16.15 & 16.78 & 7.78 & 8.48 & 10.23 \\
\hline
\end{tabular}

5) Case 5: two SGs are replaced by two DFIGs at bus 34 and bus 39 .

Table 1 Error rates of different AVR and PSS types 


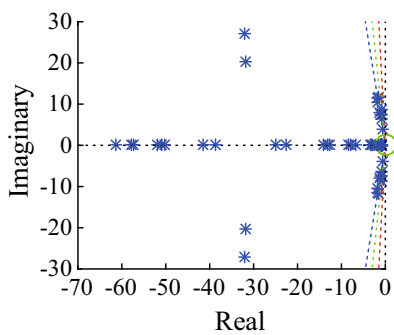

(a) Eigenvalues plot

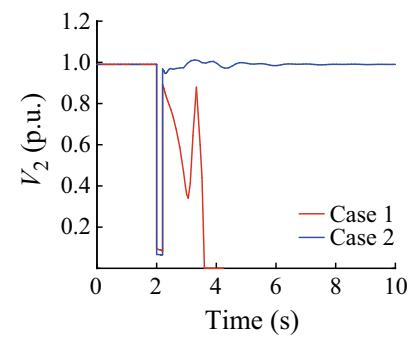

(c) Voltage magnitude at bus 2

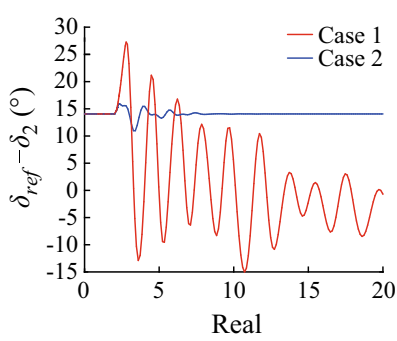

(b) Rotor angle $\delta_{r e f}-\delta_{2}$

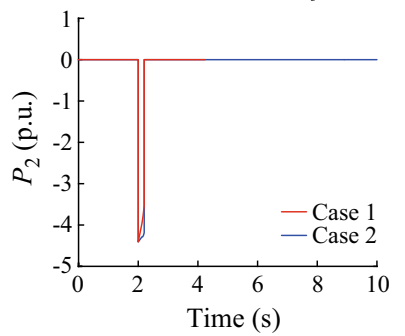

(d) Active power at bus 2

Fig. 9 Small-signal and transient responses of IEEE 39-bus system subject to a three-phase short-circuit fault for cases 1 and 2

\subsection{Case 1}

The small-signal stability analysis is performed for the considered system by adopting the first scenario and eigenvalues are extracted. Among these values, 37 have negative real parts, two are null (represented by green circle), and one has a positive real part (represented by red star) as shown in Fig. 7. These results demonstrate that the system is unstable as an eigenvalue with a positive real part exists and contributes to a negative damping ratio. The system oscillatory modes, oscillation frequency, damping ratio, and other associated states are summarized in Appendix A Table A1. Based on the oscillation frequency, the dynamic modes are classified as follows:

1) Modes 1 to 8 correspond to a local area mode with a frequency range $0.95934-1.49 \mathrm{~Hz}$.

2) Mode 9 corresponds to an inter-area mode with a frequency equal to $0.63033 \mathrm{~Hz}$.

3) Mode 10 corresponds to an eigenvalue with a positive real part. Therefore, this mode is linearly unstable.

\subsection{Case 2}

The voltage magnitude of the power system is adjusted through the addition of the excitation control system (AVRs) providing good reaction over the terminal voltage of the SGs. Consequently, the generator damping torque will be reduced at the grid oscillation frequencies. This problem can be resolved by inserting a PSS loop into the excitation system. Therefore, all the power system SGs
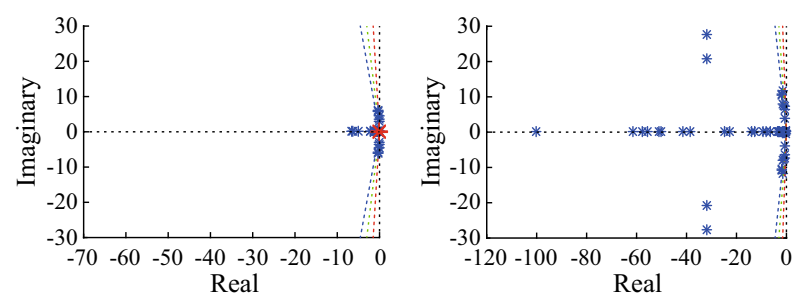

(a) DFIG (250 MW) at bus 30 for case 3

(b) DFIG (250 MW) at bus 30 for case 4

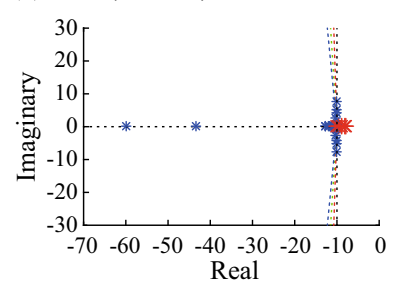

(c) DFIG (508 MW) at bus 34 for case 3
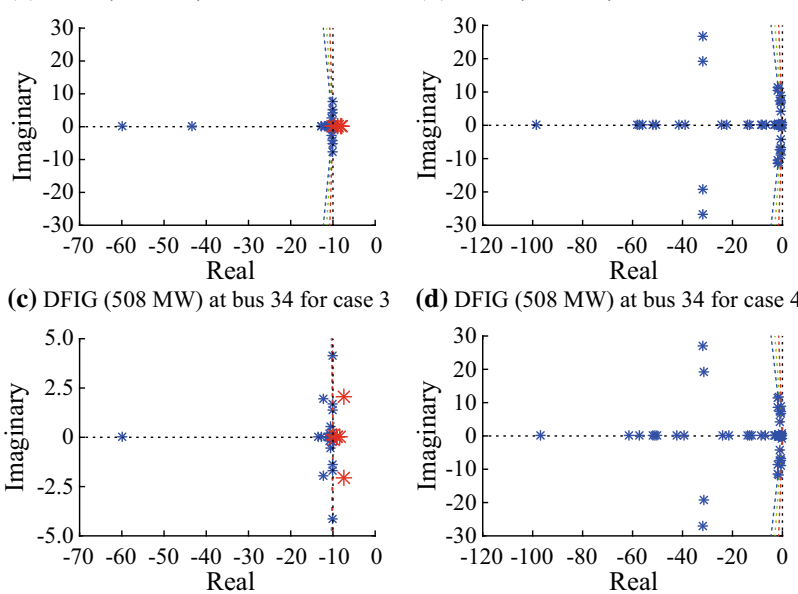

(d) DFIG (508 MW) at bus 34 for case 4

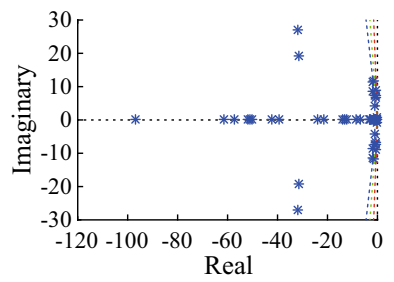

(e) DFIG (650 MW) at bus 35 for case 3

(f) DFIG (650 MW) at bus 35 for case 4
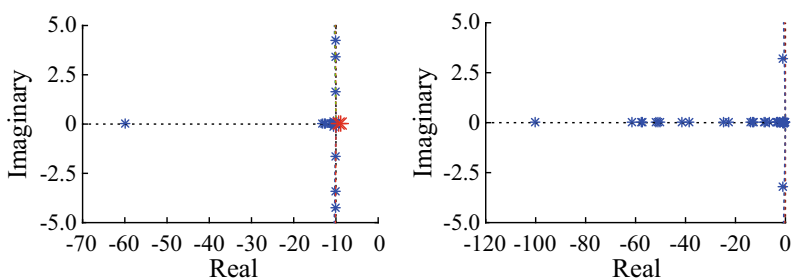

(g) DFIG (1000 MW) at bus 39 for case 3 (h) DFIG (1000 MW) at bus 39 for case 4

Fig. 10 Eigenvalues plots for cases 3 and 4

should be equipped with AVR and PSS. The performances of three different AVR and PSS combinations were examined and compared based on the maximum rotor angle deviation and the oscillation period. A three-phase short-circuit fault disturbance appears at bus 2 at $t=2 \mathrm{~s}$ and lasts for $0.2 \mathrm{~s}$. The transient response of the SG rotor angle for different AVR and PSS types is depicted in Fig. 8.

This figure indicates that the oscillations are damped out quickly from the case of AVR type 1 and type 3 to the case of AVR type 2 for different PSS models. Comparing Fig. 8a, b, and e, we conclude that AVR type 3 shows the lowest rotor angle deviation value for all PSS models. The summary of maximum rotor angle deviation rate (MRADR) and oscillation period for different AVR and PSS models is provided in Table 1. MRADR is defined as:

$$
M R A D R=\frac{\left|D_{r e f}-D_{c o n}\right|}{D_{r e f}} \times 100 \%
$$


where $D_{\text {ref }}$ and $D_{c o n}$ are the maximum rotor angle deviation under normal condition and fault condition with SG controllers.

Table 1 demonstrates that the combination of AVR type 3 and PSS type 1 yields the best oscillation damping results within the lowest period. Therefore, this controller combination is applied to all power system SGs for the following cases.

The eigenvalues plot for this case is shown in Fig. 9a and different network oscillatory mode characteristics are tabulated in Appendix A Table A1. The obtained results prove that the power system becomes stable when using AVRs and PSSs providing the best damping and an increased oscillation frequency for different modes compared with the first case. Thus, the oscillatory modes for case 2 are classified as follows: (1) modes 1-8 correspond to a local area mode; (2) mode 9 corresponds to an inter-area mode.

As shown in Fig. 9, for the initial operation condition, the power system is transiently unstable when it is subjected to a three-phase short-circuit fault. However, with the integration of controller devices, rotor angle transient oscillations are eliminated. Moreover, the voltage and active power at bus 2 remain within tolerable limits after the fault becomes cleared for case 2, thus preserving the stability of the system, reinforcing the eigenvalue results obtained in Fig. 9a.

\subsection{Case 3}

The SGs are replaced one at a time by a DFIG and only four cases with reference to DFIG power rates are presented. Figure 10 shows the system eigenvalues plots for each case. The results reveal that the replacement of SG by DFIG affects the power system stability. This conclusion is drawn from the positive real parts of eigenvalues, which contributes to a negative damping ratio. The oscillatory characteristics of the inter-area modes are provided in Appendix A Table A2. From this table, we conclude that wind energy penetration has a considerable impact in reducing the damping ratio, oscillation frequency, and mode characteristics change. Figure 11 shows the transient response of the power system to a three-phase short-circuit fault in the presence of DFIG. These plots prove that the negative effect of high-level wind generation results in a loss of synchronism for all cases. It can be concluded that the transient stability performance of SGs worsens as the share of power generation increases.

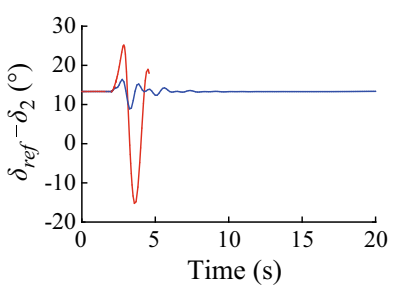

(a) DFIG (250 MW) at bus 30

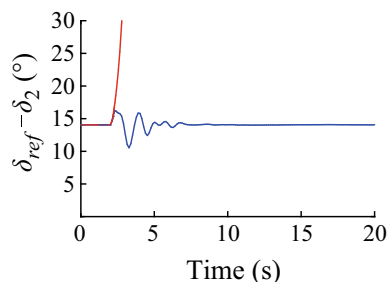

(c) DFIG (650 MW) at bus 35 - Faut condition; - Fault condition+AVR type 3+PSS type 1

Fig. 11 Transient response of rotor angle $\delta_{r e f}-\delta_{2}$ for Cases 3 and 4

\subsection{Case 4}

As observed in the preceding case, the integration of wind power in the test system exhibits a critical unstable condition owing to low damping. Thus, the addition of the chosen AVR and PSS controllers to the SGs provides better damping and stabilizes the system in the presence of a wind generator. Figure 10 illustrates the eigenvalues plots and Appendix A Table A3 summarizes the oscillatory response characteristics for the three significant modes; the highest and lowest frequency oscillation local modes and the inter-area mode. These results show that the real parts of all the eigenvalues are negative. Therefore, the system is dynamically stable. Furthermore, the damping ratio and oscillation frequency increase when inserting AVR and PSS compared with those in the other cases. Moreover, the transient response of the rotor angle depicted in Fig. 11 demonstrates the robustness of AVR and PSS controls for the damping of system oscillations in the presence of high wind generation levels.

The active output power of the wind generator, voltage, and active power characteristics at bus 2 are presented in Fig. 12. During the pre-fault, the voltage at bus 2 is estimated to be 0.99 p.u. This value falls to 0.09 p.u. during the fault. After the fault, the voltage shows some oscillations, but always lies within the stability limits for the fourth case. However, for the third case, in the absence of control devices, the voltage, active power at bus 2, and DFIG 


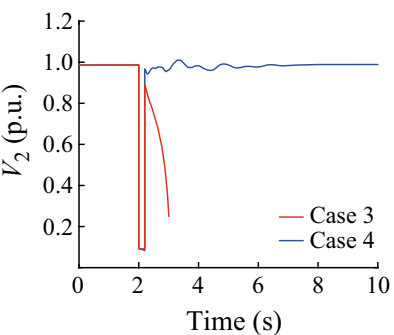

(a) Voltage magnitude at bus 2

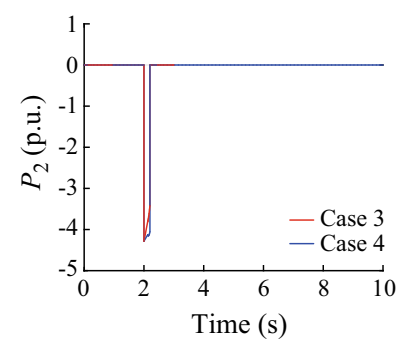

(b) Active power at bus 2

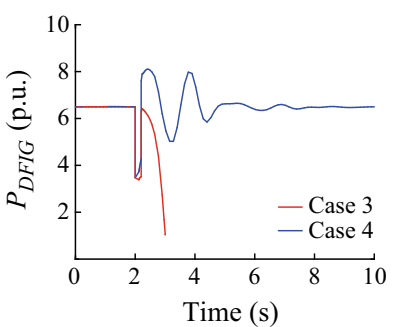

(c) Active power of DFIG

Fig. 12 Response of IEEE 39-bus system to a three-phase shortcircuit fault in the presence of DFIG at bus 35 for cases 3 and 4

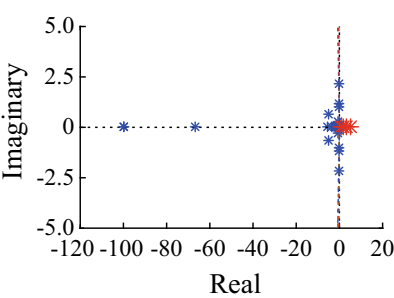

(a) Without AVR and PSS control

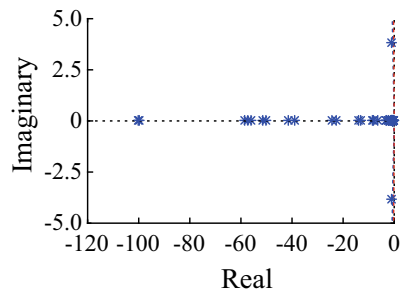

(b) With AVR and PSS control
Fig. 13 Eigenvalues plot for cases of two DFIGs

output power continue to drop, leading to power system instability.

\subsection{Case 5}

In this case, the SG at bus 34 and the one at bus 39 are replaced by two DFIGs of the same power capacity with a total power generation share of $1508 \mathrm{MW}$. Figures 13 and 14 illustrate the eigenvalues plots and the transient response of the IEEE 39-bus system in the presence of two DFIGs with and without SG controllers, respectively. The results have further shown the efficacy of the coordinated

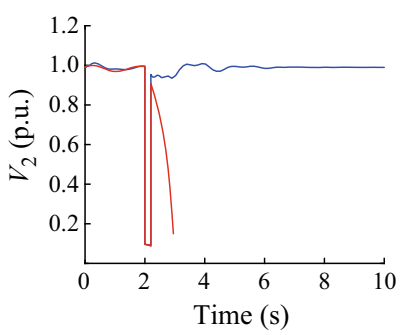

(a) Voltage magnitude at bus 2

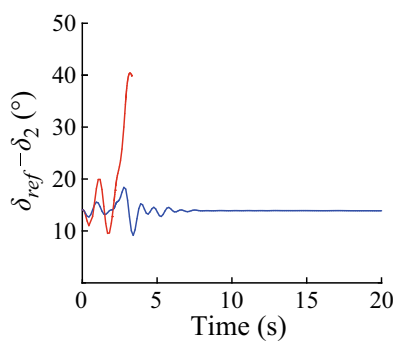

(c) Rotor angle $\delta_{\text {ref }}-\delta_{2}$

- Faut condition; - Fault condition+AVR type 3+PSS type 1

Fig. 14 Transient response of IEEE 39-bus power system for cases of two DFIGs with and without AVR and PSS control

control of AVR and PSS in preserving the small-signal and transient stabilities of the power system under high wind energy penetration levels.

\section{Conclusion}

This paper discussed the impacts of wind power penetration by DFIG on the low-frequency oscillation modes for the IEEE 39-bus New England power system. The following conclusions were drawn. The wind farm generators considerably affect the stability of the power system, leading to poor damping of the oscillatory modes. Initially, the power system is dynamically unstable and the integration of wind farms worsens this instability. Thus, SG control devices are used to provide additional damping oscillations and improve the voltage performances of the power system. Several combinations of AVRs and PSSs are investigated. The best performances are obtained with the combination of AVR type 3 and PSS type 1 in terms of oscillation damping compared with the other controller types. The integration of SG control devices allows safe 
penetration of high wind energy levels, thus ensuring the damping of local and inter-area modes.

Open Access This article is distributed under the terms of the Creative Commons Attribution 4.0 International License (http:// creativecommons.org/licenses/by/4.0/), which permits unrestricted use, distribution, and reproduction in any medium, provided you give appropriate credit to the original author(s) and the source, provide a link to the Creative Commons license, and indicate if changes were made.

\section{Appendix A}

See Tables A1, A2, and A3.

Table A1 Prevailing oscillatory modes for cases 1 and 2

\begin{tabular}{|c|c|c|c|c|c|}
\hline Case & $\begin{array}{l}\text { Mode } \\
\text { No. }\end{array}$ & Eigenvalue & $\begin{array}{l}\text { Oscillation frequency } \\
(\mathrm{Hz})\end{array}$ & $\begin{array}{l}\text { Damping } \\
\text { ratio }\end{array}$ & $\begin{array}{l}\text { Participation of the most associated states in the mode } \\
\text { control }(\%)\end{array}$ \\
\hline \multirow[t]{3}{*}{1} & 1 & $-0.14529 \pm j 6.1988$ & 0.98 & 0.023 & $\delta_{1}=36.98, \omega_{1}=36.98, \delta_{2}=11.18, \omega_{2}=11.18$ \\
\hline & 2 & $-0.22644 \pm j 3.546$ & 0.56 & 0.064 & $\delta_{9}=21.19, \omega_{9}=21.19, \delta_{4}=4.88, \omega_{4}=4.88$ \\
\hline & 3 & $0.00193 \pm \mathrm{j} 0$ & 0 & -1.000 & $\delta_{3}=12.07, \omega_{3}=12.07, \delta_{9}=23.17, \omega_{9}=23.17$ \\
\hline \multirow[t]{3}{*}{2} & 1 & $-1.318 \pm j 7.886$ & 1.26 & 0.165 & $\delta_{4}=15.44, \omega_{4}=19.19, \delta_{6}=11.79, \omega_{6}=13.44$ \\
\hline & 2 & $-0.73506 \pm j 8.799$ & 1.40 & 0.080 & $\delta_{8}=11.2, \omega_{8}=12.7, \delta_{10}=27.84, \omega_{10}=29.43$ \\
\hline & 3 & $-0.7005 \pm \mathrm{j} 3.9152$ & 0.62 & 0.180 & $\delta_{9}=16.62, \omega_{9}=16.86$ \\
\hline
\end{tabular}

Table A2 Prevailing oscillatory modes for case 3

\begin{tabular}{|c|c|c|c|c|}
\hline Mode No. & Eigenvalue & $\begin{array}{l}\text { Oscillation } \\
\text { frequency }(\mathrm{Hz})\end{array}$ & $\begin{array}{l}\text { Damping } \\
\text { ratio }\end{array}$ & $\begin{array}{l}\text { Participation of the most associated states in the } \\
\text { mode control }(\%)\end{array}$ \\
\hline \multirow[t]{5}{*}{ Bus 30} & $-0.08009 \pm \mathrm{j} 3.4439$ & 0.55 & 0.020 & $\delta_{8}=30.62, \omega_{8}=30.62, \delta_{1}=14.41, \omega_{1}=14.41$ \\
\hline & $0.0628 \pm \mathrm{j} 2.6256$ & 0.42 & 0.024 & $\delta_{1}=10.14, \omega_{1}=10.14, \delta_{2}=34.45, \omega_{2}=34.45$ \\
\hline & $6.6195 \pm \mathrm{j} 0$ & 0 & -1.000 & $\delta_{7}=27.81, \omega_{7}=27.81$ \\
\hline & $3.0075 \pm \mathrm{j} 0$ & 0 & -1.000 & $\delta_{7}=21.14$ \\
\hline & $0.64479 \pm \mathrm{j} 0$ & 0 & -1.000 & $\delta_{9}=20.62, \omega_{9}=20.62$ \\
\hline \multirow[t]{7}{*}{ Bus 34} & $-0.255 \pm \mathrm{j} 4.35$ & 0.69 & 0.059 & $\delta_{3}=16.85, \omega_{3}=16.85, \delta_{4}=12.14, \omega_{4}=12.14$ \\
\hline & $-0.63648 \pm j 2.5512$ & 0.41 & 0.240 & $\delta_{6}=28.14, \omega_{6}=28.14, e_{q 6}^{\prime}=12.75$ \\
\hline & $4.28 \pm \mathrm{j} 0$ & 0 & -1.000 & $\delta_{2}=30.74, \omega_{2}=30.74$ \\
\hline & $3.52 \pm \mathrm{j} 0$ & 0 & -1.000 & $\delta_{3}=11.56, \omega_{3}=11.56$ \\
\hline & $2.09 \pm \mathrm{j} 0$ & 0 & -1.000 & $\delta_{1}=18.12, \omega_{1}=18.12, \delta_{3}=10.26, \omega_{3}=10.26$ \\
\hline & $0.926 \pm \mathrm{j} 0$ & 0 & -1.000 & $e_{1 q 6}=44.74$ \\
\hline & $0.00614 \pm \mathrm{j} 0$ & 0 & -1.000 & $\delta_{7}=49.99, \omega_{7}=49.99$ \\
\hline \multirow[t]{6}{*}{ Bus 35} & $-0.13307 \pm \mathrm{j} 4.0974$ & 0.65 & 0.030 & $\delta_{3}=24.04, \omega_{3}=24.04, \delta_{4}=24.36, \omega_{4}=24.36$ \\
\hline & $-0.25262 \pm j 2.1079$ & 0.34 & 0.120 & $\delta_{6}=22.76, \omega_{6}=22.76, \delta_{9}=15.33, \omega_{9}=15.33$ \\
\hline & $-0.01678 \pm \mathrm{j} 1.5143$ & 0.24 & 0.011 & $\delta_{1}=13.14, \omega_{1}=13.14, \delta_{2} 18.61, \omega_{2}=18.61$ \\
\hline & $3.64 \pm \mathrm{j} 1.11$ & 0.177 & -0.950 & $\delta_{7}=13.63, \omega_{7}=13.63$ \\
\hline & $1.624 \pm \mathrm{j} 0.279$ & 0.26 & -0.987 & $\delta_{5}=11.67, \omega_{5}=11.67$ \\
\hline & $0.66 \pm \mathrm{j} 0$ & 0 & -1.000 & $\delta_{1}=12.36, \omega_{1}=12.36, \delta_{2}=17.44, \omega_{2}=17.44$ \\
\hline \multirow[t]{6}{*}{ Bus 39} & $-0.15436 \pm \mathrm{j} 3.7352$ & 0.59 & 0.041 & $\delta_{7}=43.05, \omega_{7}=43.05$ \\
\hline & $-0.10896 \pm \mathrm{j} 2.8386$ & 0.45 & 0.038 & $\delta_{2}=15.87, \omega_{2}=15.87, \delta_{8}=10.36, \omega_{8}=10.36$ \\
\hline & $-0.07332 \pm \mathrm{j} 2.5645$ & 0.41 & 0.280 & $\delta_{1}=15.35, \omega_{1}=15.35, \delta_{2}=19.39, \omega_{2}=19.39$ \\
\hline & $-0.07236 \pm \mathrm{j} 1.9801$ & 0.32 & 0.036 & $\delta_{1}=28.62, \omega_{1}=28.62$ \\
\hline & $3.83 \pm \mathrm{j} 0$ & 0 & -1.000 & $\delta_{9}=44.05, \omega_{9}=44.05$ \\
\hline & $1.77 \pm \mathrm{j} 0$ & 0 & -1.000 & $\delta_{8}=17.25, \omega_{8}=17.25$ \\
\hline
\end{tabular}


Table A3 Prevailing oscillatory modes for case 4

\begin{tabular}{|c|c|c|c|c|}
\hline $\begin{array}{l}\text { Mode } \\
\text { No. }\end{array}$ & Eigenvalue & $\begin{array}{l}\text { Oscillation frequency } \\
(\mathrm{Hz})\end{array}$ & $\begin{array}{l}\text { Damping } \\
\text { ratio }\end{array}$ & $\begin{array}{l}\text { Participation of the most associated states in the mode control } \\
(\%)\end{array}$ \\
\hline \multirow[t]{3}{*}{ Bus 30} & $-1.4524 \pm \mathrm{j} 11.6746$ & 1.8581 & 0.124 & $\delta_{3}=20.53, \omega_{3}=36.36, e_{q 3}^{\prime}=16.52$ \\
\hline & $-0.77513 \pm j 6.5459$ & 1.0418 & 0.117 & $\delta_{1}=12.06, \omega_{1}=13.12, \delta_{2}=19.74, \omega_{2}=20.76$ \\
\hline & $-0.73901 \pm \mathrm{j} 3.9794$ & 0.6300 & 0.182 & $\delta_{9}=14.67, \omega_{9}=15.02$ \\
\hline \multirow[t]{3}{*}{ Bus 34} & $-1.7407 \pm \mathrm{j} 11.4201$ & 1.8176 & 0.150 & $\delta_{6}=21.48, \omega_{6}=33.31, e_{q 6}^{\prime}=15.22$ \\
\hline & $-0.81508 \pm j 6.674$ & 1.0622 & 0.121 & $\delta_{1}=11.53, \omega_{1}=12.62, \delta_{2}=17.9, \omega_{2}=18.94$ \\
\hline & $-0.80688 \pm \mathrm{j} 4.2781$ & 0.6800 & 0.185 & $\delta_{8}=12.67, \omega_{8}=12.93$ \\
\hline \multirow[t]{3}{*}{ Bus 35} & $-1.5031 \pm \mathrm{j} 11.6039$ & 1.8468 & 0.128 & $\delta_{3}=18.75, \omega_{3}=33.17, e_{q 3}^{\prime}=15.27$ \\
\hline & $-0.81304 \pm j 6.6421$ & 1.0571 & 0.122 & $\delta_{1}=11.26, \omega_{1}=12.32, \delta_{2}=17.51, \omega_{2}=18.48$ \\
\hline & $-0.83448 \pm \mathrm{j} 4.2838$ & 0.6800 & 0.191 & $\delta_{8}=12.43, \omega_{8}=12.69$ \\
\hline \multirow[t]{3}{*}{ Bus 39} & $-1.4467 \pm \mathrm{j} 11.6549$ & 1.8549 & 0.123 & $\delta_{3}=20.09, \omega_{3}=35.55, e_{q 3}^{\prime}=16.13$ \\
\hline & $-1.0549 \pm \mathrm{j} 7.3315$ & 1.1668 & 0.142 & $\delta_{8}=21.81, \omega_{8}=23.4$ \\
\hline & $-0.834 \pm \mathrm{j} 3.21$ & 0.5100 & 0.251 & $\delta_{5}=6.64, \omega_{5}=6.64$ \\
\hline
\end{tabular}

\section{References}

[1] Khemiri N, Khedher A, Mimouni MF (2012) An adaptive nonlinear backstepping control of dfig driven by wind turbine. WSEAS Trans Environ Dev 2(8):60-71

[2] Essallah S, Bouallegue A, Khedher A (2015) Optimal placement of pv-distributed generation units in radial distribution system based on sensitivity approaches. In: Proceeding of 16th IEEE conference on sciences and techniques of automatic control and computer engineering (STA), Monastir, Tunisia, 21-23 December 2015, pp 513-520

[3] Geng H, Xi X, Yang G (2016) Small-signal stability of power system integrated with ancillary-controlled large-scale dfigbased wind farm. IET Renew Power Gener 11(8):1191-1198

[4] Bhushan R, Chatterjee K (2017) Effects of parameter variation in dfig-based grid connected system with a facts device for small-signal stability analysis. IET Gener Transm Distrib 11(11):2762-2777

[5] Xi X, Geng H, Yang G et al (2018) Two-level damping control for dfig-based wind farm providing synthetic inertial service. IEEE Trans Ind Appl 54(2):1712-1723

[6] Thakur D, Mithulananthan N (2009) Influence of constant speed wind turbine generator on power system oscillation. Electr Power Compon Syst 37(5):478-494

[7] Chopde S, Patil S (2015) Influence of grid connected solar and wind energy on small signal stability. In: Proceeding of 2015 IEEE conference on advancements in power and energy (TAP Energy), Kollam, India, 24-26 June 2015, pp 23-28

[8] Wei Z, Shaojian S (2014) The small signal stability analysis of a power system integrated with PMSG-based wind farm. In: Proceeding of 2014 IEEE conference on innovative smart grid technologies-Asia, Kuala Lumpur, Malaysia, 20-23 May 2014, pp 267-271

[9] Liu B, Guo H, Gu G (2014) Research on small-signal stability of power system connected with different wind turbines based on psat. In: Proceeding of 2014 IEEE conference on electrical machines and systems (ICEMS), Hangzhou, China, 22-25 October 2014, pp 1330-1333

[10] Banna HU, Luna A, Ying S et al (2014) Impacts of wind energy in-feed on power system small signal stability. In: Proceeding of 2014 IEEE conference on renewable energy research and application (ICRERA), Milwaukee, USA, 19-22 October 2014, pp 615-622

[11] Fernandez R, Mantz R, Battaiotto P (2007) Impact of wind farms on a power system. An eigenvalue analysis approach. Renew Energy 32(10):1676-1688

[12] Mei F, Pal BC (2006) Modal analysis of a grid connected doubly-fed induction generator. In: Proceeding of 3rd IET international conference on power electronics, machines and drives, Dublin, Ireland, 4-6 April 2006, pp 611-615

[13] Vittal V (2000) Consequence and impact of electric utility industry restructuring on transient stability and small-signal stability analysis. Proc IEEE 88(2):196-207

[14] Attya A, Hartkopf T (2012) Penetration impact of wind farms equipped with frequency variations ride through algorithm on power system frequency response. Int J Electr Power Energy Syst 40(1):94-103

[15] Bhukya J, Mahajan V (2019) Optimization of damping controller for PSS and SSSC to improve stability of interconnected system with DFIG based wind farm. Int J Electr Power Energy Syst 108:314-335

[16] Edrah M, Lo KL, Anaya-Lara O (2015) Impacts of high penetration of DFIG wind turbines on rotor angle stability of power systems. IEEE Trans Sustain Energy 6(3):759-766

[17] Darabian M, Jalilvand A (2017) A power control strategy to improve power system stability in the presence of wind farms using FACTS devices and predictive control. Int J Electr Power Energy Syst 85:50-66

[18] Bhukya J, Mahajan V (2018) Mathematical modelling and stability analysis of PSS for damping LFOs of wind power system. IET Renew Power Gener 13(1):103-115

[19] Gupta AK, Verma K, Niazi KR (2017) Dynamic impact analysis of DFIG-based wind turbine generators on low-frequency oscillations in power system. IET Gener Transm Distrib 11(18):4500-4510

[20] Jadhav HT, Roy R (2013) A comprehensive review on the grid integration of doubly fed induction generator. Int J Electr Power Energy Syst 49:8-18

[21] Kundur P (1994) Power system stability and control. McGraw Hill, New York

[22] Adjoudj L, Lakdja F, Gherbi FZ et al (2014) Synthesis integrating wind generation and facts of network. In: Proceedings of 2014 IEEE conference on electrical sciences and technologies in 
maghreb (CISTEM), Tunis, Tunisia, 3-6 November 2014, pp 1-6

[23] Bahbah AG, Girgis AA (2004) New method for generators' angles and angular velocities prediction for transient stability assessment of multimachine power systems using recurrent artificial neural network. IEEE Trans Power Syst 19(2):1015-1022

[24] Milano F (2005) An open source power system analysis toolbox. IEEE Trans Power Syst 20(3):1199-1206

[25] Karami A, Esmaili S (2013) Transient stability assessment of power systems described with detailed models using neural networks. Int $\mathrm{J}$ Electr Power Energy Syst 45(1):279-292

[26] Rao KU (2008) Computer techniques and models in power systems. IK International Pvt Ltd, New Delhi

[27] Larsen E, Swann D (1981) Applying power system stabilizers part ii: performance objectives and tuning concepts. IEEE Power Eng Rev 63:3025-3033

Sirine ESSALLAH received the B.E. degree in electrical engineering from the National Engineering School of Sousse, University of Sousse, Sousse, Tunisia, in 2013. Currently, she is a Ph.D. student at the Laboratory of Advanced Technology and Intelligent Systems, National Engineering School of Sousse, University of Sousse. Her research interests include power system analysis and control, load forecasting, distributed generation, renewable energy and distribution system planning.
Adel BOUALLEGUE received his Ph.D., the Aggregation and Electrical Engineering degrees respectively in 2006, 2000 and 1995. Currently, he is a teacher with Industrial Electronics Department, National Engineering School of Sousse (ENISO), University of Sousse, Tunisia. He is a researcher at the LATIS Lab in emerging electrical fields and particularly in Smart Grids and AMI. Moreover, $\mathrm{He}$ is a Consultant and has established very solid link with many Tunisian industries working in the field of electric distribution, smart metering, and embedded systems. His research interests include smart transformers, vehicle wireless battery charger and energy forecasting and efficiency in smart grids.

Adel KHEDHER received the Master of Sciences and DEA degrees from ENSET, Tunis, Tunisia, in 1991 and 1994, respectively. He gets his Ph.D. and HDR degrees from ENIS, Sfax, Tunisia in 2006 and 2012 respectively. From 1995 to 2002, he had been a training teacher in the professional training centers. From 2003 to 2006, he had been an assistant professor in the Electronic Engineering Department of ISSATS, Sousse, Tunisia. He has been promoted to the associate professor grade in the same department since June 2006. From September 2010, he has been an associate professor in the Industrial Electronic Engineering Department of ENISO, Sousse, Tunisia. He has been promoted to the Full professor grade in Electrical Systems in the same department since November 2012. His research interests include the control of the conventional and nonconventional static converters, the electric machine drives, the renewable and green energy systems and the smart grid. 